\title{
$\begin{array}{r}\text { WAGENINGEN } \\ \text { UNIVERSITY \& RESEARCH } \\ \hline\end{array}$
}

\section{Chaotropic heat treatment resolves native-like aggregation of a heterologously produced hyperthermostable laminarinase}

Westphal, A. H., Geerke-Volmer, A. A., van Mierlo, C. P. M., \& van Berkel, W. J. $\mathrm{H}$.

This article is made publically available in the institutional repository of Wageningen University and Research, under article 25fa of the Dutch Copyright Act, also known as the Amendment Taverne.

Article $25 \mathrm{fa}$ states that the author of a short scientific work funded either wholly or partially by Dutch public funds is entitled to make that work publicly available for no consideration following a reasonable period of time after the work was first published, provided that clear reference is made to the source of the first publication of the work.

For questions regarding the public availability of this article, please contact openscience.library@wur.nl.

Please cite this publication as follows:

Westphal, A. H., Geerke-Volmer, A. A., van Mierlo, C. P. M., \& van Berkel, W. J. H. (2017). Chaotropic heat treatment resolves native-like aggregation of a heterologously produced hyperthermostable laminarinase. Biotechnology Journal, 12(6), [1700007]. https://doi.org/10.1002/biot.201700007 


\title{
Chaotropic heat treatment resolves native-like aggregation of a heterologously produced hyperthermostable laminarinase
}

\author{
Adrie H. Westphal ${ }^{1}$, Astrid A. Geerke-Volmer ${ }^{1,2}$, Carlo P. M. van Mierlo ${ }^{1}$ and Willem J. H. van Berkel ${ }^{1}$ \\ 'Laboratory of Biochemistry, Wageningen University \& Research, Wageningen, The Netherlands \\ ${ }^{2}$ Present address: Technology \& Support, Aspen Oss B.V., Oss, The Netherlands
}

Production of hyperthermostable enzymes in mesophilic hosts frequently causes undesired aggregation of these proteins. During production of Pyrococcus furiosus endo- $\beta$-1,3-glucanase (LamA) in Escherichia coli, soluble and insoluble species form. Here, the authors address the composition of this mixture, including the nature of LamA conformers, and establish a method to increase the yield of native monomer. With gel electrophoresis, size-exclusion chromatography, light scattering, circular dichroism and enzyme kinetics the authors show that approximately $50 \%$ of heterologously produced LamA is soluble, and that $40 \%$ of this fraction constitutes native-like oligomers and non-native monomers. Soluble oligomers display, like native LamA monomer, substrate inhibition, although with poor activity. Treatment of soluble oligomers with $3 \mathrm{M}$ guanidinium hydrochloride at $80^{\circ} \mathrm{C}$ yields up to $75 \%$ properly active monomer. Non-native monomer shows low specific activity without substrate inhibition. Incubating non-native monomer with $3 \mathrm{M}$ guanidinium hydrochloride at $80^{\circ} \mathrm{C}$ causes formation of $25 \%$ native LamA. Also, a large amount of insoluble LamA aggregates can be converted into soluble native monomer by application of this procedure. Thus, chaotropic heat treatment can improve the yield and quality of hyperthermostable proteins that form aberrant species during production in E. coli.

$\begin{array}{ll}\text { Received } & \text { 05 JAN } 2017 \\ \text { Revised } & \text { 10 APR } 2017 \\ \text { Accepted } & 11 \text { APR } 2017 \\ \text { Accepted } & \\ \text { article online } & 12 \text { APR } 2017\end{array}$

Supporting information available online

Keywords: Biocatalysis - Endoglucanase - Glycosyl hydrolase · Protein expression · Protein stability

\section{Introduction}

Hyperthermostable proteins are increasingly used in, among others, biocatalysis, DNA processing and polymer degradation [1-3]. Their extraordinary stability and activity under extreme conditions attracted attention of academia and industry. Nowadays, a considerable number of this class of proteins is produced at large scale using mesophilic hosts. A commonly used host for heterologous

Correspondence: Prof. Willem J. H. van Berkel, Laboratory of Biochemistry, Wageningen University \& Research, Stippeneng 4, 6708 WE, Wageningen, The Netherlands

E-mail:willem.vanberkel@wur.nl

Abbreviations: DLS, dynamic light scattering; $\mathrm{GuHCl}$, guanidine hydrochloride; IBs, inclusion bodies; IPTG, isopropyl- $\beta$-D-7-thiogalactoside; LamA, laminarinase A; Ni-NTA, nickel-nitrilotriacetate; PAGE, polyacrylamide gel electrophoresis; SEC, size exclusion chromatography; SDS, sodium dodecyl sulfate; s.d., standard deviation protein expression is the mesophilic prokaryote Escherichia coli [4], which is easy to transform, has a large range of expression strains and generally yields high levels of protein. However, folding of especially hyperthermostable proteins in its crowded cytoplasm may not always proceed correctly, resulting in formation of substantial amounts of soluble and/or insoluble aggregates [5-8].

In cells, ribosomes are responsible for synthesizing proteins by translating mRNA into polymers of amino acids. Within prokaryotes, this translation can start even before transcription of the mRNA has finished $[9,10]$. A nascent polypeptide chain potentially starts to fold inside the ribosomal exit tunnel, which can encompass elements with $\alpha$-helical structure. Upon subsequent emergence from the ribosome, chaperone proteins hovering at the ribosomal exit tunnel can start to interact with the nascent chain and affect its folding [11-13]. In E. coli, a cluster of ribosomes can adhere to mRNA and this so-called polysome translates several proteins concomitantly [14]. The ribosomes in a polysome are organized in such a manner that the distance 
between adjacently produced polypeptides is maximized. This reduces the probability of intermolecular interactions that possibly leads to protein aggregation [15]. Chaperones also protect against aggregation, because they prevent hydrophobic patches of nascent chains to be exposed to the crowded cytoplasm [13]. However, strong overexpression of a protein can exceed the capacity of the chaperone system, which can lead to misfolding, misassembly and/or oligomerization of the unprotected protein chains. Aggregation is enhanced if these misfolded proteins are not effciently degraded by proteases [16]. Ultimately, these events can induce formation of insoluble aggregates, called bacterial inclusion bodies (IBs) [11, 17-22].

Within E. coli, depending on the over-expressed protein, a large number of small aggregates of different sizes can form that loosely associate to form bigger aggregates [17]. Also, formation of a single large aggregate in a cell by continuous deposition of protein molecules on a nucleation seed is observed [23]. E. coli cells that contain inclusion bodies or fluffy, looser, flocculated material are often abnormally elongated and can contain a large variety of cellular aggregates [24]. It is suggested that soluble aggregates might be intermediates in the formation of inclusion bodies and/or during disaggregation of inclusion bodies [21].

Formation of inclusion bodies happens during the expression of many heterologous proteins. To recover biologically active protein, inclusion bodies are isolated and solubilized, and the target protein is refolded to its native structure. Using a chaotropic agent, like urea or guanidine hydrochloride ( $\mathrm{GuHCl})$, a reducing agent to break disulfide bonds, and alkaline $\mathrm{pH}$, commonly solubilizes inclusion bodies (see e.g. [25-30]). Refolding is often achieved by diluting the denaturant through addition (or exchange) of buffer, or by using liquid chromatography (chromatographic refolding) like size-exclusion chromatography [27]. High pressure treatment, either in the absence or presence of chaotropic agent, can also be useful to foster refolding of proteins from inclusion bodies [31, 32].

According to computational studies, hyperthermostable proteins have folding energy landscapes that differ from their mesophilic counterparts [33]. At moderate temperatures, folding intermediates of hyperthermostable proteins are likely more stable than mesophilic ones and thus have higher propensity to aggregate in $E$. coli. As a consequence, oligomerization may be significant during overexpression of a hyperthermostable protein in this mesophilic host. The resulting aggregates need not be all converted into IBs, nor degraded by proteases, and potentially remain in solution. In the investigation presented here, we focus on characterizing the soluble forms of a heterologously produced hyperthermostable glycosyl hydrolase. These forms include non-native monomers and oligomeric protein. We use and evaluate chaotropic heat treatment of these soluble forms. Also, we report the effect this treatment has on the corresponding inclusion bodies.
Endo- $\beta$-1,3-glucanase (LamA, EC 3.2.1.39) from the hyperthermophilic archaeon Pyrococcus furiosus is one of the most heat stable glycosyl hydrolases reported to date, displaying optimal activity at $104^{\circ} \mathrm{C}$ [34]. This enzyme is excreted by $P$. furiosus as a monomer of $31 \mathrm{kDa}[34,35]$. Recombinant LamA monomer has been isolated from E. coli [35] and characterized, using, among others, NMR spectroscopy [36] and X-ray crystallography [37]. Here, we show that a significant portion of heterologously produced LamA comprises insoluble aggregates, soluble oligomers and non-native monomers, and address the properties of these species. Native LamA is exceptionally persistent to denaturation by $\mathrm{GuHCl}$ [38]. We exploit this property to develop a procedure to disrupt soluble and non-soluble LamA aggregates and increase the amount of properly folded active LamA monomer.

\section{Materials and methods}

\subsection{Materials}

Restriction enzymes NcoI and XhoI were purchased from New England Biolabs GMBH (Frankfurt am Main, Germany). T4 DNA ligase, Pfu DNA polymerase and dNTPs came from Thermo Fisher Scientific (Breda, The Netherlands). Primers were purchased from Eurogentec S.A. (Seraing, Belgium). E. coli strains BL21(DE3) and BL21 pRare-LysS (Rosetta pLysS), expression vector pET24-d(+), and polyvinylidene fluoride membrane (Immobilon-P) were from Merck Millipore (Merck Chemicals B.V., Amsterdam, The Netherlands). Isopropyl- $\beta$-D-1-thiogalactoside, kanamycin, Terrific broth and LB broth low salt were obtained from Duchefa Biochemie (Haarlem, The Netherlands). Nickelnitrilotriacetate (Ni-NTA) agarose was purchased from Qiagen Benelux BV (Venlo, The Netherlands). Superdex 75 10/300 GL column, ribonuclease A, chymotrypsinogen and Blue Dextran were obtained from Pharmacia Biotech/GE Healthcare BV (Eindhoven, The Netherlands). Ovalbumin, BSA, Nile red and laminarin were from Sigma-Aldrich BV (Zwijndrecht, The Netherlands). Low-range SDS-PAGE standards, Bradford protein assay kit and Biogel P6-DG came from Bio-Rad (Veenendaal, The Netherlands). All other chemicals were from commercial sources such as Sigma-Aldrich, Merck or Acros.

\subsection{Plasmid construction}

Two primers were used to amplify DNA that codes for LamA without $\mathrm{N}$-terminal signal sequence (amino acids 35-297) (5'-CCGCCATGGTCCCTGAAGTGATAGAAA 'TAGATGG-3' and 5'-GCGCTCGAGACCACTAAGAAT GAGTAAACCC-3'). Underlined bases represent recognition sites for NCoI and Xhol, respectively. Genomic DNA of $P$. furiosus was used as template [34]. PCR product was obtained using Pfu DNA polymerase, with first 10 cycles 
containing an annealing temperature of $53^{\circ} \mathrm{C}$, followed by 25 cycles containing an annealing temperature of $58^{\circ} \mathrm{C}$. pLamA-His 6 (6025 bp) was constructed by ligating the PCR fragment (789 bp) into plasmid pET24-d(+), after restriction of both units with $\mathrm{NCOI}$ and XhoI. Successful cloning was confirmed by automated sequencing (Macrogen Europe, Amsterdam, The Netherlands). Constructs of pLamA-His 6 were electroporated into E. coli strains BL21(DE3) or Rosetta pLysS.

\subsection{LamA production}

E. coli BL21(DE3) cells harboring pLamA-His ${ }_{6}$ were inoculated into Terrific broth medium supplemented with $50 \mathrm{mg} \mathrm{L}^{-1}$ kanamycin, incubated in a shaker incubator $(250 \mathrm{rpm})$ at $37^{\circ} \mathrm{C}$. When cell optical density $\left(\mathrm{OD}_{600}\right)$ reached 0.8 , protein production was initiated by adding isopropyl- $\beta$-D-1-thiogalactoside (IPTG) to a final concentration of $0.4 \mathrm{mM}$, followed by shaking at $250 \mathrm{rpm}$ for an additional $18 \mathrm{~h}$ at $37^{\circ} \mathrm{C}$. Cells were harvested by centrifugation at $11000 \times g$ for $15 \mathrm{~min}$ at $4^{\circ} \mathrm{C}$. Cell pellets were flash frozen with liquid $\mathrm{N}_{2}$ and stored at $-20^{\circ} \mathrm{C}$.

\subsection{Time, temperature and inducer-concentration dependent LamA production}

Three 0.5 L cultures were inoculated with E. coli BL21(DE3) cells harboring plasmid pLamA-His ${ }_{6}$ and grown at $37^{\circ} \mathrm{C}$. At an optical density $\left(\mathrm{OD}_{600}\right)$ of 0.8 , one culture was induced with $0.1 \mathrm{mM}$ IPTG and a second with $0.4 \mathrm{mM}$ IPTG, and both were incubated further at $37^{\circ} \mathrm{C}$. The third culture was induced with $0.4 \mathrm{mM}$ IPTG and incubated at $28^{\circ} \mathrm{C}$. From each culture, $5 \mathrm{~mL}$ samples were taken at 0, 1, 2, 4 and $20 \mathrm{~h}$ after induction, respectively. Optical density was determined at $600 \mathrm{~nm}$ and cells were harvested by centrifugation at $4140 \times g$ for $15 \mathrm{~min}$. The obtained cell pellets were resuspended in buffer (50 mM sodium phosphate, pH 6.5), assuring that equal amounts of cells per volume were present in each sample (i.e. about $3.2 \times 10^{9} \mathrm{cells} \mathrm{mL}^{-1}$; an $\mathrm{OD}_{600}$ of 1.0 was assumed to correspond to about $10^{9}$ cells $\mathrm{mL}^{-1}$ ). To lyse the cells, four freeze-thaw cycles were applied, followed by centrifugation (16 $100 \times g, 10 \mathrm{~min}$ ). Protein in supernatant was analysed using native polyacrylamide gel electrophoresis (PAGE) and Western blotting.

\subsection{Enzyme purification}

A pellet of $E$. coli cells, expressing LamA, was resuspended in a volume of cold buffer A (50 mM sodium phosphate, $\mathrm{pH}$ 6.5, containing $50 \mathrm{mM}$ imidazole and $0.5 \mathrm{M} \mathrm{NaCl}$ ), equal to the weight of the pellet, followed by three passages through a precooled French pressure cell, operating at 16000 psi. After each cycle, the sample was cooled. Subsequent centrifugation at $39000 \times g$ for $45 \mathrm{~min}$ at $4^{\circ} \mathrm{C}$ yielded cell extract. Next, cell extract was placed in a water bath of $80^{\circ} \mathrm{C}$ for $30 \mathrm{~min}$, followed by centrifugation at $39000 \times g$ for $15 \mathrm{~min}$ at $4^{\circ} \mathrm{C}$. The resulting supernatant was subjected to Ni-NTA affinity chromatography. Before applying the sample, the Ni-NTA column $(15 \times 160 \mathrm{~mm})$ was equilibrated with buffer A (50 mM sodium phosphate, pH 6.5, containing $50 \mathrm{mM}$ imidazole and $0.5 \mathrm{M}$ $\mathrm{NaCl}$ ). After loading the sample, the column was washed with buffer $A$ until $A_{280}$ of eluent reached base-line level. LamA was eluted with a gradient of $0-100 \%$ buffer B (50 mM sodium phosphate, $\mathrm{pH} 6.5$, containing $0.5 \mathrm{M}$ imidazole and $0.5 \mathrm{M} \mathrm{NaCl}$ ) in 10 column volumes. Finally, Superdex $75(10 \times 300 \mathrm{~mm})$ gel filtration in $50 \mathrm{mM}$ sodium phosphate, pH 6.5, containing $150 \mathrm{mM} \mathrm{NaCl}$, yielded three species of LamA with differing hydrodynamic properties. To obtain pure samples of each species, gel filtration was repeated twice. Relative ratios of LamA species were estimated by integrating the corresponding elution peaks monitored at $280 \mathrm{~nm}$.

\subsection{Chaotropic heat treatment of soluble LamA species}

LamA species were mixed with $\mathrm{GuHCl}$, resulting in LamA concentrations of $2-4 \mathrm{mg} \mathrm{mL}^{-1}$ and $\mathrm{GuHCl}$ concentrations ranging from 0 to $3 \mathrm{M}$. Samples were incubated up to $5 \mathrm{~h}$ at $80^{\circ} \mathrm{C}$, then diluted two-fold with $50 \mathrm{mM}$ sodium phosphate, pH 6.5, and subjected to Superdex 75 analytical gel filtration at room temperature. Relative ratios of LamA species were estimated by integrating the corresponding elution peaks monitored at $280 \mathrm{~nm}$.

\subsection{Aggregate visualization and inclusion body treatment}

E. coli cells expressing LamA were stained using Nile red. One milliliter of culture was centrifuged at $13000 \times g$ for $5 \mathrm{~min}$ and the pellet was resuspended in $1 \mathrm{~mL}$ of $\mathrm{MiliQ}$ water. Subsequently, $40 \mu \mathrm{L}$ of a Nile red solution (80 $\mu \mathrm{g} \mathrm{mL} \mathrm{m}^{-1}$, dissolved in dimethyl sulfoxide) was added to the cell suspension, and this mixture was incubated at room temperature for $30 \mathrm{~min}$. After subsequent centrifugation at $13000 \times g$ for $5 \mathrm{~min}$, the supernatant was discarded. MiliQ water ( $1 \mathrm{~mL}$ ) was added to the resulting pellet, followed by vigorous vortexing. An aliquot of the suspension was pipetted into an eight-wells microplate. Cells settled at the bottom of the well were imaged using a Zeiss LSM 510 confocal microscope fitted with a 40x Zeiss C Apochromat, NA 1.2, water immersion objective. Excitation wavelength used was $543 \mathrm{~nm}$ and emission was collected using a bandpass filter (560-615 nm).

A $500 \mathrm{~mL}$ culture of $E$. coli cells expressing LamA was centrifuged at $5000 \times g$ for $15 \mathrm{~min}$ at $4^{\circ} \mathrm{C}$. The cell pellet was resuspended in a volume of cold $50 \mathrm{mM}$ sodium phosphate buffer, pH 6.5, equal to the weight of the pellet, followed by three passages through a precooled French pressure cell operating at 16000 psi. Sample was cooled after each cycle. Half of the resulting French pressure cell sample 
(FP) was centrifuged at $45000 \times g$ for $45 \mathrm{~min}$ at $4^{\circ} \mathrm{C}$, yielding cell-free extract $(\mathrm{CFE})$ and pellet. An amount of buffer (50 mM sodium phosphate, pH 6.5), equal to the volume of $\mathrm{CFE}$, was used to obtain resuspended pellet (rPellet). Samples from all fractions were treated with $3 \mathrm{M} \mathrm{GuHCl}$ at $80^{\circ} \mathrm{C}$ for $3 \mathrm{~h}$. After centrifugation of $\mathrm{GuHCl}$-treated samples at $45000 \times g$ for $45 \mathrm{~min}$ at $4^{\circ} \mathrm{C}$, supernatants, pellets and untreated samples were analyzed using SDS-PAGE, and the amount of LamA protein was quantified and assayed for LamA activity. To assess reproducibility, the above described procedure was performed three times with separately grown cultures of $E$. coli cells expressing LamA.

\subsection{Protein analysis}

Protein content was analyzed using Bradford protein assay reagent and BSA as reference protein. The amount of LamA protein in crude samples was determined using SDS-PAGE. SDS-PAGE gels were loaded with samples and with a range of known amounts of pure LamA. After staining with Coomassie Brilliant Blue and destaining, gels were scanned (Biorad scanner) and the obtained peaks from each lane were integrated. The amount of LamA in raw samples was determined using the peak area of the band migrating at the LamA height and a calibration plot constructed from peak-areas against the corresponding quantities of LamA. LamA species were analyzed by Western blotting. Proteins separated by native PAGE were transferred to Immobilon-P membranes by electro-blotting o/n at $20 \mathrm{~V}$ using transfer buffer (10 mM CAPS, pH 11, containing 10\% v/v methanol). Membranes were subsequently treated during $1 \mathrm{~h}$ incubations with blocking buffer (20 mM Tris-Cl, pH 7.5, $150 \mathrm{mM} \mathrm{NaCl}, 0.1 \% \mathrm{w} / \mathrm{v}$ Tween 20 and 1\% w/v gelatine), rabbit anti-LamA antiserum (diluted 1:500 in blocking buffer) as primary antibody, and goat anti-rabbit IgG alkaline phosphatase conjugate (diluted 1:10 000 in blocking buffer) as secondary antibody. Membranes were incubated with 5-bromo-4-chloro-3-indolyl-phosphate and nitro blue tetrazolium. Stained protein bands resulted if alkaline phosphatase was present.

Enzyme purity was analyzed using SDS-PAGE. Protein samples were heated for $30 \mathrm{~min}$ at $99^{\circ} \mathrm{C}$ in loading buffer (0.1 M Tris-Cl, 4\% SDS, 10\% 2-mercaptoethanol, $20 \%$ glycerol, $0.02 \%$ bromophenol blue, $\mathrm{pH}$ 6.8) prior to gel application [39]. Native PAGE was used to estimate the relative contribution of LamA species with differing hydrodynamic properties.

Analytical size exclusion chromatography (SEC) was performed on a Superdex 75 10/300 GL column, running in $50 \mathrm{mM}$ sodium phosphate buffer, pH 6.5, with $150 \mathrm{mM}$ $\mathrm{NaCl}$. Fractions containing LamA oligomers were collected from 7.0 to $11.0 \mathrm{~mL}$, fractions containing nonnative LamA monomer from 11.0 to $13.5 \mathrm{~mL}$ and fractions containing native LamA monomer from 13.5 to $16.5 \mathrm{~mL}$. Ribonuclease A (13.7 kDa), chymotrypsinogen (25 kDa), ovalbumin (43 kDa) and BSA (67 kDa) served as reference proteins, acetone $(2 \%)$ was used as total volume $\left(V_{t}\right)$ marker and Blue Dextran $(2000 \mathrm{kDa})$ as void volume $\left(V_{0}\right)$ marker. Partition coefficients $\left(K_{\mathrm{av}}\right)$ were calculated using peak elution volumes of corresponding proteins $\left(V_{\mathrm{e}}\right)$ according to the following equation:

$K_{a V}=\frac{\left(V_{\mathrm{e}}-V_{0}\right)}{\left(V_{\mathrm{t}}-V_{0}\right)}$

Dynamic light scattering (DLS) was performed using a Zetasizer Nano ZS (Sysmex Netherlands BV, Etten-Leur, The Netherlands). Data were processed using the CONTIN algorithm [40]. Filtered protein samples of $1 \mathrm{mg} \mathrm{mL}^{-1} \mathrm{LamA}$ in $50 \mathrm{mM}$ sodium phosphate, $\mathrm{pH} 7.4$, were measured at $632.8 \mathrm{~nm}$ at a fixed angle of $173^{\circ}$. Each sample - in propylene cuvettes - was measured 10 times and signal was averaged. Viscosity and refractive index values of samples were assumed to be equal to those of water at $20^{\circ} \mathrm{C}$.

Far-UV CD spectra were obtained using $61.4 \mu \mathrm{g} \mathrm{mL}^{-1}$ LamA in 10 mM sodium phosphate, pH 6.5. All LamA samples had similar absorption values at $280 \mathrm{~nm}$. Use was made of a J-815 CD spectrophotometer (Jasco Europe s.r.l., Cremella, Italy) with a Jasco CDF-426s temperature controller, set at $20^{\circ} \mathrm{C}$. Parameters used were: bandwidth of $5 \mathrm{~nm}$, time constant of $0.5 \mathrm{~s}$, scan rate of $100 \mathrm{~nm} \mathrm{~min}^{-1}$, and scan averaging set at 20. Spectra were recorded in $0.1 \mathrm{~cm}$ quartz cuvettes and were corrected by subtracting CD spectra of buffer solution recorded under identical conditions.

LamA activity was measured using an adapted 3,5-dinitrosalicylate assay [41]. In short, $50 \mu \mathrm{L}$ of LamA solution $\left(20-200 \mu \mathrm{g} \mathrm{mL}^{-1}\right)$ was mixed with $950 \mu \mathrm{L}$ laminarin solution (5 $\mathrm{mg} \mathrm{mL}^{-1}$ ), both in $50 \mathrm{mM}$ sodium phosphate, $\mathrm{pH} 6.5$, and incubated for $20 \mathrm{~min}$ at $80^{\circ} \mathrm{C}$. At 5 min intervals, samples of $100 \mu \mathrm{L}$ were taken and mixed with $100 \mu \mathrm{L}$ of assay mixture $(1.6 \% \mathrm{w} / \mathrm{v} \mathrm{NaOH}, 1.0 \% \mathrm{w} / \mathrm{v}$ 3.5-dinitrosalicylic acid, $0.2 \% \mathrm{w} / \mathrm{v}$ phenol, $0.05 \% \mathrm{w} / \mathrm{v}$ sodium sulfite, $30 \% \mathrm{w} / \mathrm{v}$ sodium potassium tartrate) and incubated for $5 \mathrm{~min}$ at $95^{\circ} \mathrm{C}$. Samples were cooled on ice, diluted with $1 \mathrm{~mL}$ water, and absorbance was measured at $575 \mathrm{~nm}$. The concentration of laminarin hydrolysis products was inferred from absorbance at $575 \mathrm{~nm}$ using samples of glucose, ranging in concentration from 0 to $8 \mathrm{mM}$, assayed under similar conditions. One unit of enzyme activity is defined as the amount of enzyme required for releasing one $\mu$ mole of laminarin hydrolysis product per min.

For estimation of steady-state kinetic parameters, the LamA activity assay contained different amounts of laminarin ranging from 0 to $5.5 \mathrm{mM}$. Every data point was retrieved in triplicate. Using IGOR Pro 6.10A, apparent rates $\left(v_{\text {app }}\right)$ were fitted to the Haldane equation, taking substrate inhibition into account:

$$
V_{\text {app }}=\frac{V_{\max } \cdot[S]}{K_{\mathrm{M}}+[S]+\left(\frac{[S]^{2}}{K_{\mathrm{i}}}\right)}
$$


where $[S], V_{\max }, K_{\mathrm{M}}$ and $K_{\mathrm{i}}$ represent the substrate concentration, the limiting rate, the Michaelis constant and the inhibition constant, respectively.

\section{Results}

\subsection{Heterologously produced, soluble LamA comprises native and non-native monomers as well as oligomers}

Purification of $\mathrm{His}_{6}$-tagged LamA, obtained after heterologous expression in $E$. coli, involves cell disruption, heat treatment and metal-affinity chromatography. After these steps, the LamA sample consists of a mixture of species, which can be separated using SEC (Fig. 1A). Native PAGE of samples from SEC elution shows the presence of native monomer, non-native monomer and oligomers (Fig. 1C). SDS-PAGE applied to these samples shows that the unfolded species all have the same subunit molecular mass (Fig. 1D). Distinction between native and nonnative species is made based on data and argumentation provided below. No rapid dynamic equilibrium exists between the obtained LamA species, because, even after multiple freeze-thaw cycles, or six months of storage at $-20^{\circ} \mathrm{C}$, or exposure to room temperature for several weeks, we obtain unaltered SEC profiles (data not shown). The short heat treatment applied during LamA purification also has no significant effect on LamA oligomerization (data not shown). Hence, we conclude that formation of the mixture of LamA species arises during production within E. coli.

Dynamic light scattering (DLS) shows that both native as well as non-native LamA monomers have the typical dimension of a globular protein of approximately $31 \mathrm{kDa}$ [42] and that the oligomer sample comprises several high molecular mass species (Supporting information, Table S1).

Native LamA monomer elutes with a larger volume from the Superdex 75 SEC column as expected from its mass (Fig. 1B). We ascribe this increase in elution volume to weak affinity of native LamA for the Superdex matrix, which consists of agarose/dextran polysaccharides. Interestingly, nonnative LamA monomer has no such affinity for this column material and elutes at the expected volume (Fig. 1B).

\subsection{Soluble oligomers display, like native LamA monomer, substrate inhibition, whereas non-native monomer does not}

The maximal specific activity $\left(V_{\max }\right)$ of the mixture of LamA species obtained after Ni-NTA chromatography, as assayed with 3,5 -dinitrosalicylate at $80^{\circ} \mathrm{C}$, is $1389 \pm 19$ (U mg ${ }^{-1} \pm$ s.d.) (Table 1). This blend of native and nonnative monomers as well as oligomers shows substrate inhibition (Fig. 2A, Table 1). Native LamA monomer has a $V_{\max }$ of $1894 \pm 76$ (U mg ${ }^{-1} \pm$ s.d.) and displays enhanced substrate inhibition (Fig. 2B, Table 1). This supports the presence of a secondary binding site for laminarin in LamA [3]. The catalytic efficiency $\left(k_{\mathrm{cat}} / K_{\mathrm{M}}\right)$ of native LamA monomer is about $5.5 \times 10^{6} \mathrm{M}^{-1} \mathrm{~s}^{-1}$, which is higher than the values reported previously [3, 34], where SEC was not included in LamA purification. Non-native LamA monomer is 4.4-fold less active than native monomer, since its $V_{\max }$ is only $427 \pm 19\left(\mathrm{U} \mathrm{mg}^{-1} \pm\right.$ s.d.) (Table 1). Interestingly, this conformer lacks substrate inhibition and follows normal Michaelis-Menten kinetics (Fig. 2C, Table 1), but shows a higher $K_{\mathrm{M}}$ value compared to that of native protein. LamA oligomer is enzymatically active, but its $V_{\max }$ of $406 \pm 7$ ( $\mathrm{U} \mathrm{mg}^{-1} \pm$ s.d.) shows that the oligomer is 4.7-fold less active than native monomer (Fig. 2D, Table 1). Just as native monomer, oligomers exhibit substrate inhibition, suggesting that these particles comprise protein with a native-like fold. The relatively low activity of oligomer probably arises from hampered access of the rather large substrate (i.e. laminarin, $\pm 3 \mathrm{kDa}$ ) to active sites buried inside the oligomer, which is reflected in higher $K_{\mathrm{M}}$ and $K_{\mathrm{i}}$ values compared to those of native LamA monomer.

\subsection{The secondary structure of protein in LamA oligomer resembles more the one of native LamA monomer than of non-native LamA monomer}

The far-UV circular dichroism (CD) spectrum of native LamA monomer is characteristic for a protein containing $\beta$-strands [43] (Fig. 3A, green line). This observation reflects the characteristics of the crystal structure of LamA, which consists of a sandwich-like $\beta$-jelly roll motif formed by face-to-face packing of two anti-parallel sheets that contain seven and eight strands, respectively (Fig. 3B) [35]. Non-native LamA monomer has a far-UV CD spectrum that is also typical for a $\beta$-strand containing protein (Fig. 3A, red line), but its ellipticities at 190, 205 and $230 \mathrm{~nm}$ and the crossing of its ellipticity at 207-208 $\mathrm{nm}$ with the $\mathrm{x}$-axis differ from those observed for native monomer. These dissimilarities suggest a slightly diminished $\beta$-strand content in non-native LamA compared to native monomer. In case of LamA oligomer, its ellipticity at about $190 \mathrm{~nm}$ is decreased and its ellipticity at $230 \mathrm{~nm}$ is slightly increased compared to the values that characterize native LamA monomer (Fig. 3A, blue line). The zero crossing of the ellipticity of LamA oligomer at $206 \mathrm{~nm}$ is at a similar wavelength as observed for native LamA monomer. These observations indicate that the secondary structure of protein in LamA oligomer resembles more the one of native LamA monomer than of non-native LamA monomer.

\subsection{Formation of LamA oligomers takes place in $E$. coli}

Emergence of non-native and aggregation-prone LamA species can occur during several stages of protein pro- 
A

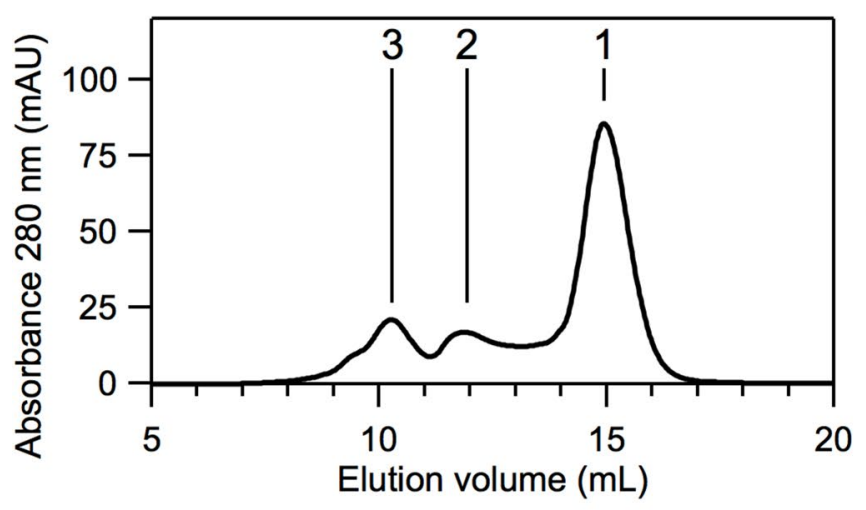

C

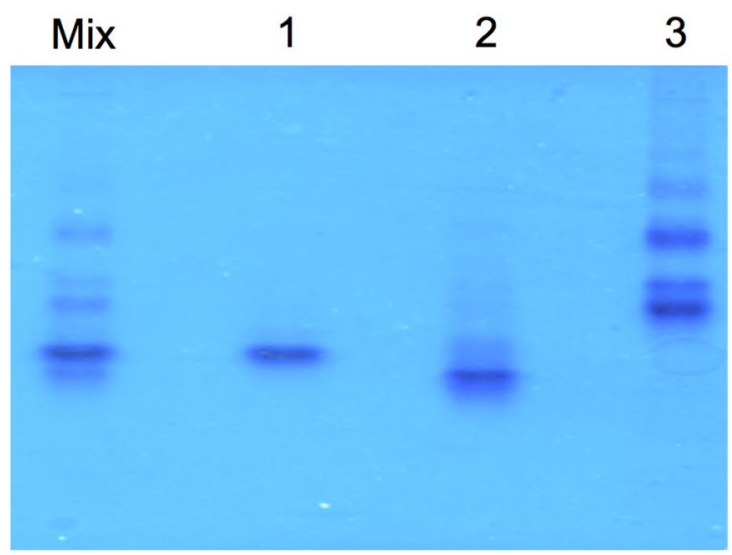

B
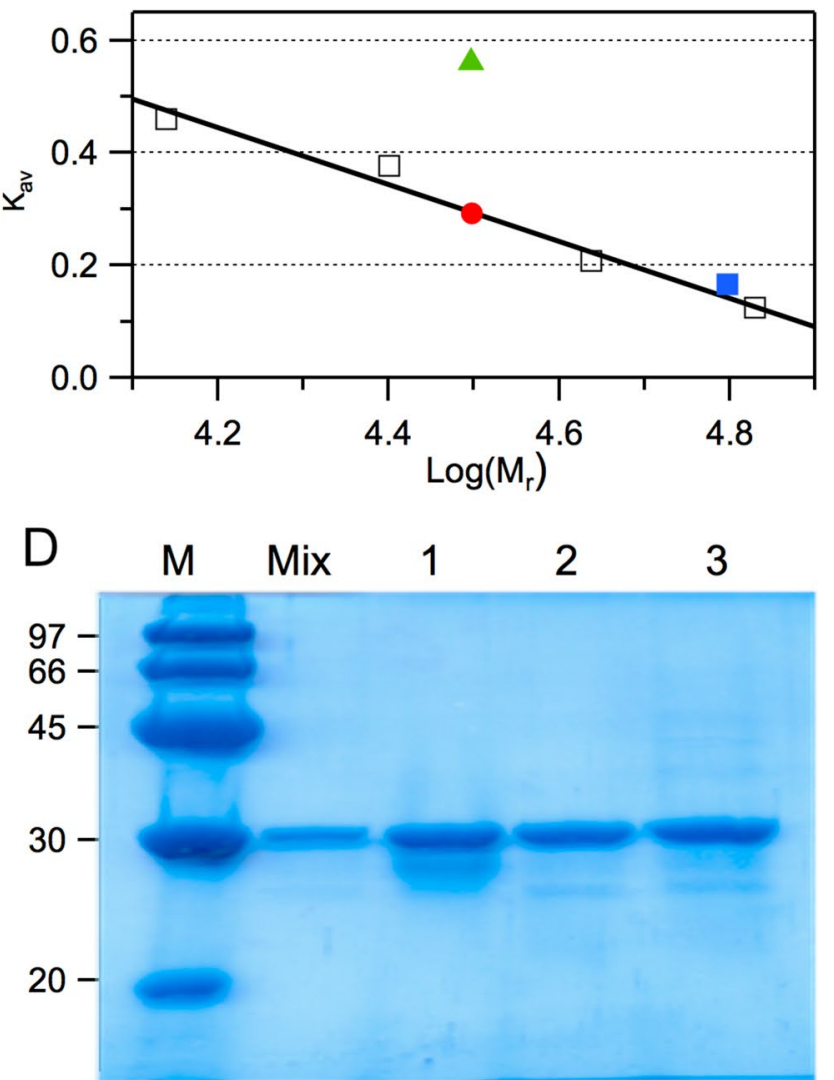

Figure 1. Hydrodynamic properties of purified LamA. (A) SEC-elution pattern (Superdex 75) of LamA obtained after Ni-NTA affinity chromatography. (B) Retention of LamA on Superdex 75. Partition coefficients (Kav) are plotted against the logarithms of the corresponding molecular masses ( $\mathrm{M}_{\mathrm{r}}$ ): LamA monomer (green triangle), LamA non-native monomer (red circle), LamA oligomer (blue square). Reference proteins (open squares): ribonuclease $A$ (13.7 kDa), chymotrypsinogen (25 kDa), ovalbumin (43 kDa) and BSA (67 kDa). (C) Western blot after native PAGE. (Mix), mixture of LamA species obtained using Ni-NTA chromatography; (1) native monomers; (2) non-native monomers; (3) oligomers. Panel (D) SDS-PAGE. (Mix), mixture of LamA species obtained using Ni-NTA chromatography; (1) native monomers; (2) non-native monomers; (3) oligomers. Lane M, Low-range SDS-PAGE standards with their masses indicated $(\mathrm{kDa})$.

duction in $E$. coli. Rare-codon usage in the gene encoding LamA may lead to temporary stalling of ribosomes, which slows down protein translation and could enhance aggregation [44]. However, low protein yield is not an issue in case of LamA because an expression level of up to $15 \%$ of total cellular protein is reached [34]. Sequence analysis shows that of the 272 codons of the LamA gene, 21 are infrequently used in $E$. coli genes. To verify whether this feature relates to proper LamA folding, plasmid pLamA-His ${ }_{6}$ was transformed into E. coli strain Rosetta (DE3)pLysS, which contains an additional plasmid to relieve rare-codon usage in heterologous genes. Neither protein yield nor oligomerization level differs compared to LamA isolated from cells lacking this auxiliary plasmid, as SEC reveals. Changing other parameters (i.e. production time, induction conditions or growth temperature) does also not alter the composition of the mixture of species (Supporting information, Fig. S1).

\subsection{Chaotropic heat treatment disrupts soluble LamA aggregates and increases the amount of properly folded active LamA monomer}

Native LamA, even under extreme conditions, does not easily unfold. For example, in $7.9 \mathrm{M} \mathrm{GuHCl}$ at room temperature, the unfolded state of LamA is not fully populated [38, 45, 46]. In the following, we exploit this characteristic feature.

To gain insight into the reversibility of LamA oligomerization, we analyzed the hydrodynamic properties of LamA after treating oligomer samples with $\mathrm{GuHCl}$ at elevated temperature and various incubation periods. Significant dissociation of oligomer at $80^{\circ} \mathrm{C}$ occurs at high GuHCl concentration (Fig. 4A, left part). Up to 75\% conversion to the desired monomeric species is observed after an incubation period of $5 \mathrm{~h}$ in $3 \mathrm{M} \mathrm{GuHCl}$ (Fig. 4A, right part). The monomeric species formed has the same hydrodynamic properties and secondary structure com- 
A

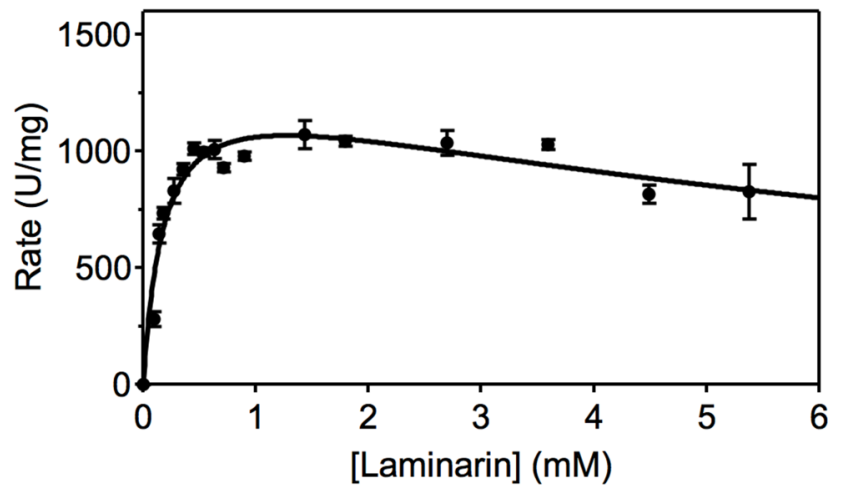

C

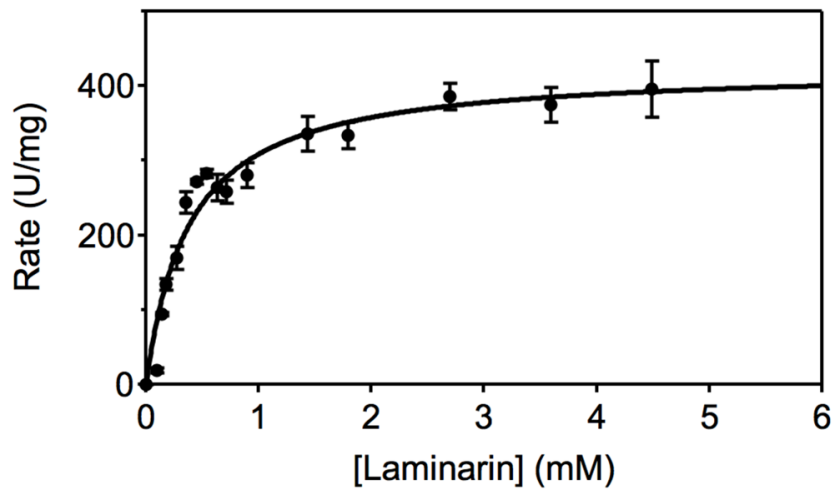

B

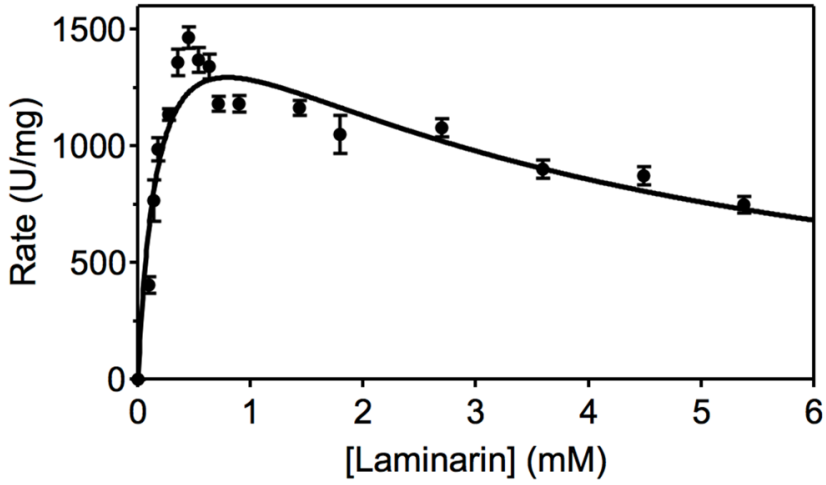

D

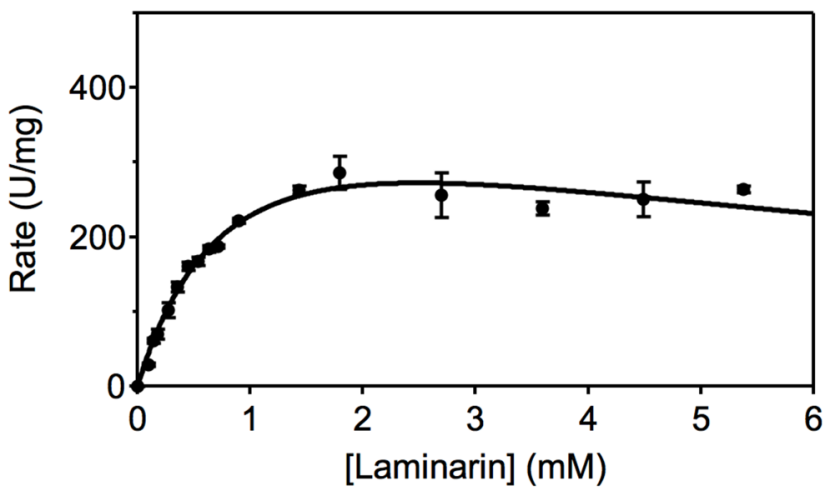

Figure 2. Steady-state kinetics of LamA. The Haldane model, including substrate inhibition, has been used to fit the data. (A), Mixture of LamA species obtained using Ni-NTA chromatography. (B) Native monomeric LamA. (C), Non-native monomeric LamA. (D) Oligomeric LamA. Vertical bars represent standard errors. Table 1 summarizes the kinetic constants obtained from the fitting procedure.

Table 1. Kinetic parameters of LamA species obtained after Ni-NTA chromatography and of subsequently SEC-purified LamA conformers. Activity measurements were performed in triplicate

\begin{tabular}{|c|c|c|c|c|}
\hline Species & $\begin{array}{l}V_{\max } \\
\left(U^{m g^{-1}}\right)\end{array}$ & $\begin{array}{l}K_{\mathrm{M}} \\
(\mathrm{mM})\end{array}$ & $\begin{array}{l}K_{\mathrm{i}} \\
(\mathrm{mM})\end{array}$ & $\begin{array}{l}k_{\text {cat }} \\
\left(s^{-1}\right)\end{array}$ \\
\hline Mixture & $1389 \pm 19$ & $0.19 \pm 0.03$ & $9 \pm 2$ & $722 \pm 10$ \\
\hline Native monomer & $1894 \pm 76$ & $0.18 \pm 0.03$ & $3.4 \pm 0.3$ & $984 \pm 39$ \\
\hline Non-native monomer & $427 \pm 19$ & $0.38 \pm 0.06$ & - & $222 \pm 10$ \\
\hline Oligomers & $406 \pm 7$ & $0.80 \pm 0.05$ & $14 \pm 2$ & $211 \pm 4$ \\
\hline
\end{tabular}

position as native monomer, as judged by SEC analysis and CD spectroscopy (Supporting information, Fig. S2). During oligomer dissociation, a small amount of nonnative monomeric LamA forms (Fig. 4A), which also happens upon treating native monomer for a period of $3 \mathrm{~h}$ with $3 \mathrm{M} \mathrm{GuHCl}$ at $80^{\circ} \mathrm{C}$ (Fig. 4B). A similar incubation of non-native LamA leads to formation of about $25 \%$ native LamA, as well as some oligomer.

Incubation of the mixture of LamA species, obtained after Ni-NTA chromatography, in $3 \mathrm{M} \mathrm{GuHCl}$ at $80^{\circ} \mathrm{C}$ for $3 \mathrm{~h}$ leads to disappearance of almost all oligomer species and results in $90 \%$ native and $9 \%$ non-native monomers, respectively
(Fig. 4B). The specific activity of this sample is $950 \pm 50 \mathrm{U} \mathrm{mg}^{-1}$, which is in good agreement with specific activity of native monomer assayed under similar conditions.

We can describe the observed results with the following equilibrium scheme:

non- native $\rightleftarrows$ native $\rightleftarrows$ aggregation - prone $\rightleftarrows$ oligomer

During production in E. coli, native, non-native and aggregation-prone LamA is produced, and the latter can form oligomer. Due to their large stability, no rapid equilibrium exists between these species. Addition of dena- 
A
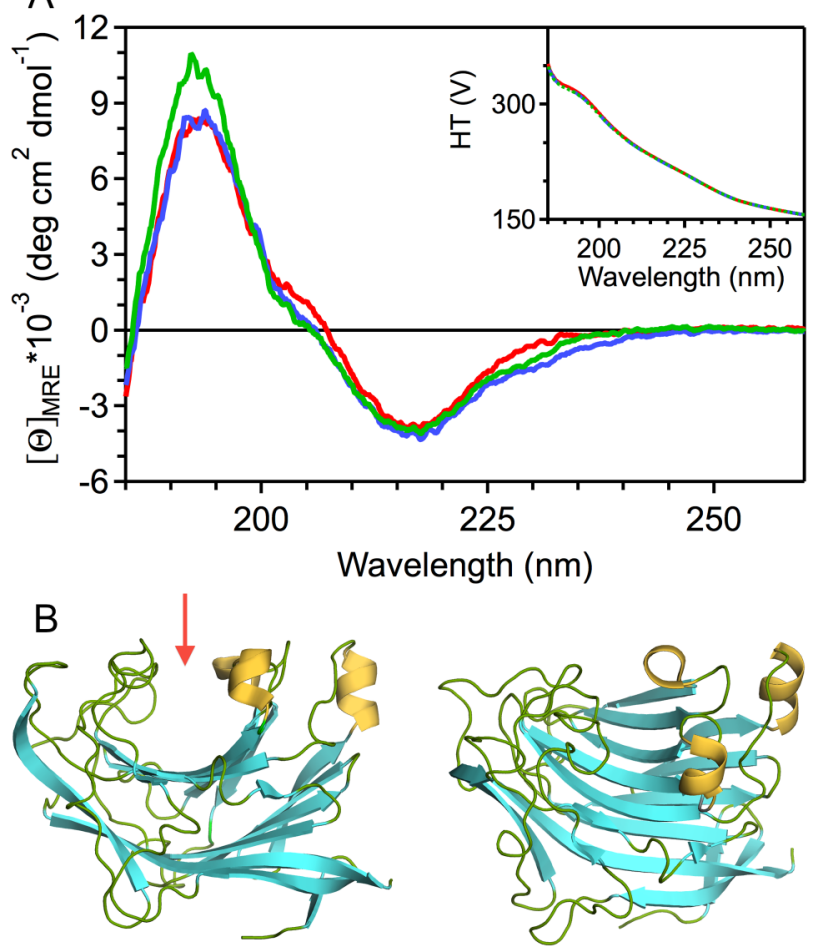

Figure 3. Structural characteristics of LamA species. (A) Far-UV CD spectra. Native monomer (green line); non-native monomer (red line); oligomers (blue line). The inset shows that the high-tension voltage traces are identical, which is indicative for an equal amount of protein in the samples (i.e. $2.0 \mu \mathrm{M})$. Spectra were recorded at $20^{\circ} \mathrm{C}$. (B) Cartoon representation of the crystal structure of LamA (pdb entry $2 \mathrm{vy} 0$ ). The left image highlights the presence of a double layer of bend $\beta$-sheets and an arrow indicates the groove for substrate binding. In the right image, the LamA molecule is rotated to show the relatively large amount of $\beta$-sheet present in the protein.

turant, in combination with high temperature, shifts the equilibrium towards native LamA.

\subsection{Chaotropic heat treatment disrupts non-soluble LamA aggregates and recovers properly folded active LamA monomer}

Part of LamA produced by E. coli ends up in IBs. Confocal microscopy images of Nile red stained E. coli cells overexpressing LamA show high fluorescence intensity at the cell poles (Fig. 4C), matching the typical distribution pattern of protein present in IBs. To assess the prospect of recovering soluble LamA from these IBs, we applied the chaotropic heat treatment procedure. Cell-free extract (referred to as CFE sample) was obtained as supernatant upon centrifugation of overexpressing cells disrupted by French press treatment (referred to as FP sample). The pellet obtained after centrifugation was resuspended in buffer (referred to as rPellet sample) and, together with the FP and CFE samples, assayed for amount of LamA protein and LamA activity. Of the total quantity of LamA protein present in the FP sample, $(54 \pm 4) \%$ ends up in the rPellet fraction (Fig. 4D).

Incubation of $\mathrm{CFE}$ with $3 \mathrm{M} \mathrm{GuHCl}$ at $80^{\circ} \mathrm{C}$ for $3 \mathrm{~h}$, followed by centrifugation, results in an increase in LamA specific activity of the supernatant from $575 \pm 23 \mathrm{U} \mathrm{mg}^{-1}$ to $952 \pm 40 \mathrm{U} \mathrm{mg}^{-1}$ (Fig. 4E), in agreement with the outcomes of similar treatment of samples obtained from Ni-NTA chromatography. LamA present in the rPellet fraction is active (226 $\pm 10 \mathrm{U} \mathrm{mg}^{-1}$ ), and re-centrifugation of rPellet shows only marginal activity of the resulting supernatant $\left(10 \pm 5 \mathrm{U} \mathrm{mg}^{-1}\right)$, confirming the presence of insoluble LamA aggregates. Incubation of rPellet with $3 \mathrm{M} \mathrm{GuHCl}$ at $80^{\circ} \mathrm{C}$ for $3 \mathrm{~h}$, followed by centrifugation, yields a strong increase in LamA specific activity $\left(719 \pm 29 \mathrm{U} \mathrm{mg}^{-1}\right)$ of the supernatant (Fig. 4E). SEC analysis of the subsequently dialyzed LamA sample shows an elution pattern almost similar to that of native LamA monomer (data not shown).

Finally, it should be stressed that it is the combination of chemical denaturant and high temperature that is essential in increasing the yield of native LamA monomer. Treatment of rPellet with $3 \mathrm{M} \mathrm{GuHCl}$ at $20^{\circ} \mathrm{C}$ for $3 \mathrm{~h}$, or heating at $80^{\circ} \mathrm{C}$ without denaturant for $3 \mathrm{~h}$, results in poor recovery of LamA activity (Supporting information, Fig. S3).

\section{Discussion}

In this paper, we demonstrate that a large fraction of hyperthermostable, heterologously produced LamA comprises insoluble aggregates, soluble oligomer and nonnative monomer. The mesophilic nature of $E$. coli is the main determinant for the persistence of these anomalous LamA species. The stability of native LamA, its oligomer and its non-native monomer against (sub)global unfolding is considerable and, as a consequence, chaperones of E. coli fail to assist these aberrant protein forms in folding towards native LamA. As shown by Peng et. al., re-hosting the $P$. furiosus chaperone systems to $E$. Coli cells indeed increases the soluble expression of a recombinant $\alpha$-amylase from $P$. furiosus [47]. In addition, cellular proteases are apparently incapable of degrading the highly stable aberrant LamA species, as we isolate these in considerable quantities from $E$. coli.

Formation of native-like protein aggregates has attracted considerable attention, as it can occur in living organisms and thus is more relevant than previously thought $[20,48]$. Here, we demonstrate that the soluble LamA oligomers formed in $E$. coli are composed of nativelike molecules, because these oligomers are enzymatically active and show substrate inhibition just like native LamA does. In addition, the far-UV CD spectrum of LamA oligomer is similar to that of native enzyme. Oligomer LamA is, at $80^{\circ} \mathrm{C}$, in slow equilibrium with native and non-native LamA. Upon addition of $\mathrm{GuHCl}$, this equilibrium can be largely shifted towards native monomer, while the amount of non-native LamA only slightly 
A

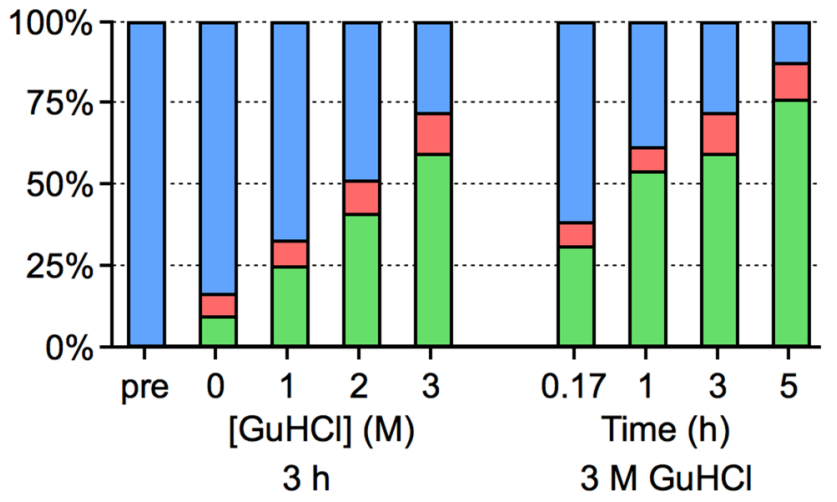

B

C
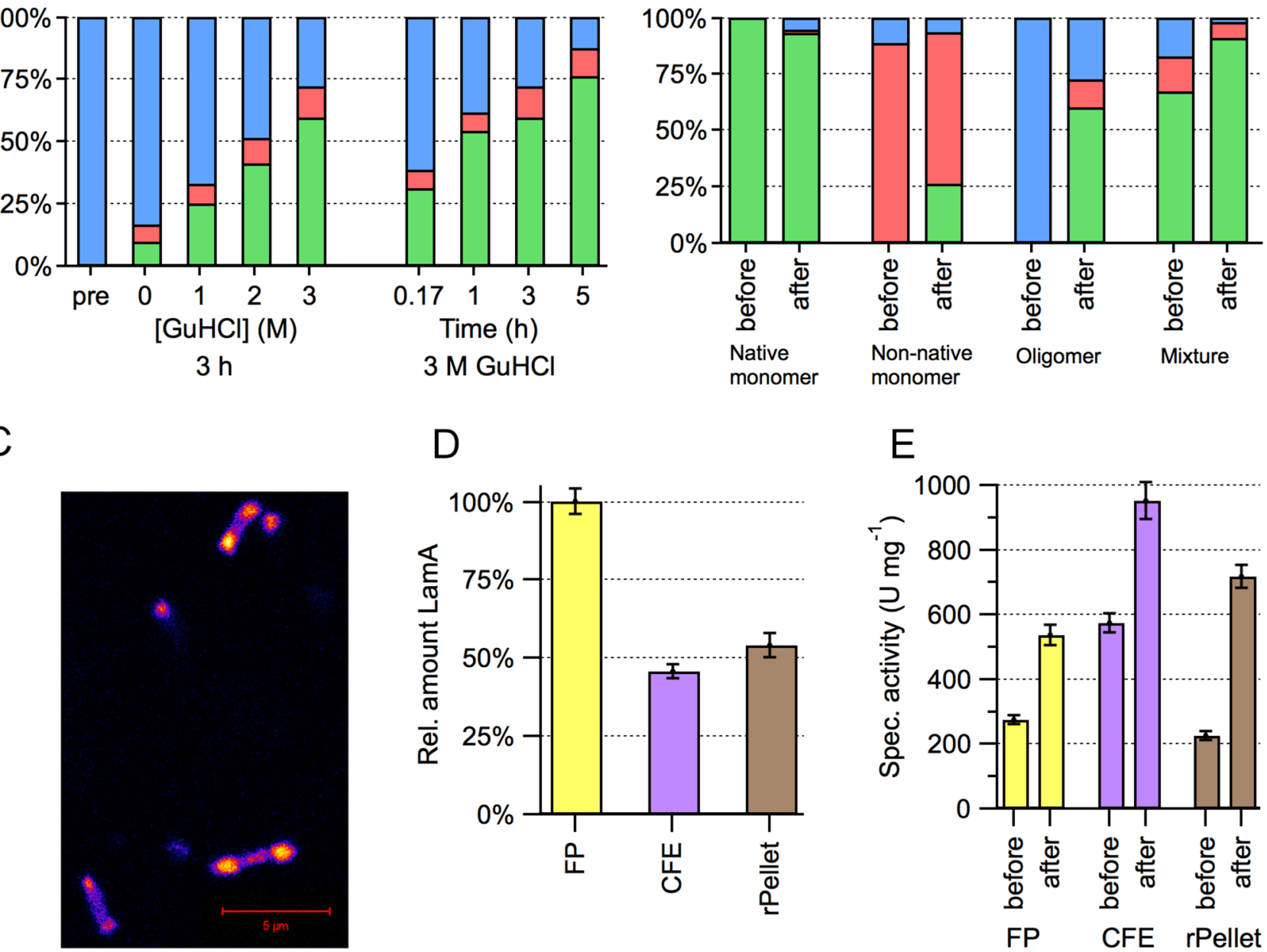

Figure 4. Chaotropic heat treatment of LamA species. (A) Relative ratios of protein species observed with $\mathrm{SEC}$ after incubating oligomer at $80^{\circ} \mathrm{C}$ with $\mathrm{GuHCl}$ at the indicated conditions. The bar representing the sample before treatment is labeled 'pre'. Color scheme: oligomer (blue), non-native monomer (red), native monomer (green). (B) relative ratio of protein species observed with SEC after incubation of native monomer, non-native monomer, oligomer and a mixture of LamA species with $3 \mathrm{M} \mathrm{GuHCl}$ at $80^{\circ} \mathrm{C}$ for $3 \mathrm{~h}$. Color scheme: oligomer (blue), non-native monomer (red), native monomer (green). The standard error on the data is $\pm 4 \%$. (C) Confocal microscope image of Nile red stained E. coli cells that overexpress LamA. (D) relative amounts of LamA present in French press (FP), cell-free extract (CFE) and resuspended pellet (rPellet) samples. Color scheme: FP (yellow), CFE (purple), rPellet (brown). Vertical bars represent standard errors. (E), specific activities of LamA in supernatants of FP, CFE and rPellet samples before and after incubation with $3 \mathrm{M}$ $\mathrm{GuHCl}$ at $80^{\circ} \mathrm{C}$ for $3 \mathrm{~h}$. Color scheme: FP (yellow), CFE (purple), rPellet (brown). Vertical bars represent standard errors.

increases. This supports our finding that LamA oligomer is composed of an aggregation prone native-like species.

When native LamA is incubated with $3 \mathrm{M} \mathrm{GuHCl}$ at $80^{\circ} \mathrm{C}$, almost no oligomer forms and only a small amount of non-native monomer is observed. In contrast, when non-native monomer undergoes this chaotropic heat treatment, an appreciable amount of native LamA forms. These findings demonstrate that under these harsh conditions, a significant shift in equilibrium towards the native state occurs. Native LamA resides in a deep energetic minimum in the energy landscape of LamA folding and is separated from other LamA conformers by energetically high transition states. As a result, treatment of native LamA monomer with $3 \mathrm{M} \mathrm{GuHCl}$ at $80^{\circ} \mathrm{C}$ for a period of $3 \mathrm{~h}$ hardly leads to formation of non-native monomer and oligomers (Fig. 4B). In the folding energy landscape, non-native LamA monomer is positioned in a distinct, less deep energetic minimum, which is separated from native and oligomeric LamA species by energetically high transition states. As a result, Fig. 4B shows that treatment of non-native LamA monomer leads to appreciable formation of native LamA monomer (i.e. about $25 \%$ recovery) and some oligomer formation. Oligomeric LamA, however, is in an even less deep energetic minimum and is surrounded by energetically less high transition states than is the case for both native and nonnative monomeric protein, as our chaotropic heat treatment of oligomers shows significant formation of native 
LamA monomer (Fig. 4B). This observation reflects the native-like nature of LamA monomer in these oligomers (i.e. the oligomers are catalytically active, display substrate inhibition, and have secondary structure resembling the one of native LamA). Apparently, the intermolecular interactions between the monomers in oligomeric LamA are substantially weaker than the intramolecular interactions in both native and non-native LamA monomer.

We show that due to differences in affinities for Superdex beads, native LamA monomers can be separated from nonnative ones. The catalytic efficiency of native LamA $\left(k_{\mathrm{cat}} / K_{\mathrm{M}}\right)$ is about one order of magnitude higher than that of nonnative LamA and shows, in contrast to the latter species, substrate inhibition. Based on these kinetic properties and on the behavior in SEC, we propose that the affinity of native LamA for Superdex beads is due to presence of a secondary sugar-binding site, which lacks in non-native monomer. The observed differences in CD spectra of native and non-native LamA suggests a decreased amount of $\beta$-strands in the nonnative species, which may explain the absence of the secondary binding site.

Conventional purification of heterologously produced LamA involves heat treatment of $E$. coli extract and subsequent chromatographic steps [35]. These procedures result in relatively low yields of LamA monomer. We show that this is due to the presence of (in)soluble LamA aggregates and non-native LamA monomers. The yield of native, properly active, LamA monomer can be increased more than two-fold by incubating the soluble and insoluble LamA fractions with $3 \mathrm{M} \mathrm{GuHCl}$ at $80^{\circ} \mathrm{C}$. We argue that this chaotropic heat treatment is effective, because $\mathrm{GuHCl}$ increases the aqueous solubility of the hydrophobic surfaces of the aberrant protein species [49], and because GuHCl hardly affects the structure of native LamA [38].

We thank Misha Denis, Thijs Gerritzen, Mark Levisson and Remco Fokkink for assistance. The Institute for Sustainable Process Technology (ISPT), Amersfoort, The Netherlands, supported AAGV through project SC-00-02.

The authors declare no commercial or financial conflict of interest.

\section{References}

[1] Vieille, C., Zeikus, G. J., Hyperthermophilic enzymes: sources, uses, and molecular mechanisms for thermostability. Microbiol. Mol. Biol. Rev. 2001, 65, 1-43.

[2] Antranikian, G., Industrial relevance of thermophiles and their enzymes, in: Robb, F., Antranikian, G., Grogan, D., Driessen, A. (Ed.), Thermophiles: Biology and Technology at high Temperatures, CRC Press, New York 2008, pp. 113-160.

[3] Przybysz, A., Volmer, A., Westphal, A. H., van Berkel, W. J. H., Bifunctional immobilization of a hyperthermostable endo B-1,3-glucanase. Appl. Micobiol. Biotechnol. 2013, 98, 1155-1163.
[4] Makrides, S. C., Strategies for achieving high-level expression of genes in Escherichia coli. Microbiol. Rev. 1996, 60, 512-538.

[5] Ellis, R. J., Minton, A. P., Cell biology: join the crowd. Nature 2003, 425, 27-28.

[6] Baneyx, F., Mujacic, M., Recombinant protein folding and misfolding in Escherichia coli. Nat. Biotechnol. 2004, 22, 1399-1408.

[7] Huijbers, M. M. E., van Berkel, W. J. H., High yields of active Thermus thermophilus proline dehydrogenase are obtained using maltosebinding protein as a solubility tag. Biotechnol. J. 2015, 10, 395-403.

[8] Sriyapai, T., Somyoonsap, P., Matsui, K., Kawai, F. et al., Cloning of a thermostable xylanase from Actinomadura sp. S14 and its expression in Escherichia coli and Pichia pastoris. J. Biosci. Bioeng. 2011, $111,528-536$

[9] Miller, O. L.-J., Hamkalo, B. A., Thomas, C. A.-J., Visualization of bacterial genes in action. Science 1970, 169, 392-395.

[10] Schmeing, T. M., Ramakrishnan, V., What recent ribosome structures have revealed about the mechanism of translation. Nature 2009, 461, 1234-1242.

[11] Ellis, R. J., Protein misassembly: Macromolecular crowding and molecular chaperones. Adv. Exp. Med. Biol. 2007, 594, 1-13.

[12] Fedyukina, D. V., Cavagnero, S., Protein folding at the exit tunnel. Annu. Rev. Biophys. 2011, 40, 337-359.

[13] Hartl, F. U., Bracher, A., Hayer-Hartl, M., Molecular chaperones in protein folding and proteostasis. Nature 2011, 475, 324-332.

[14] Slayter, H., Kiho, Y., Hall, C., Rich, A., An electron microscopic study of large bacterial polyribosomes. J. Cell. Biol. 1968, 37, 583-590.

[15] Brandt, F., Etchells, S. A., Ortiz, J. O., Elcock, A. H. et al., The native 3D organization of bacterial polysomes. Cell 2009, 136, 261-271.

[16] Dougan, D. A., Mogk, A., Bukau, B., Protein folding and degradation in bacteria: to degrade or not to degrade? That is the question. Cell. Mol. Life Sci. 2002, 59, 1607-1616.

[17] Baneyx, F., Recombinant protein expression in Escherichia coli. Curr. Opin. Biotechnol. 1999, 10, 411-421.

[18] Dobson, C. M., Protein folding and misfolding. Nature 2003, 426, 884-890.

[19] Tyedmers, J., Mogk, A., Bukau, B., Cellular strategies for controlling protein aggregation. Nat. Rev. Mol. Cell. Biol. 2010, 11, 777-788.

[20] Gatti-Lafranconi, P., Natalello, A., Ami, D., Doglia, S. M. et al., Concepts and tools to exploit the potential of bacterial inclusion bodies in protein science and biotechnology. FEBS J. 2011, 278, 2408-2418.

[21] Garcia-Fruitos, E., Sabate, R., de Groot, N. S., Villaverde, A. et al., Biological role of bacterial inclusion bodies: a model for amyloid aggregation. FEBS J. 2011, 278, 2419-2427.

[22] Hartl, F. U., Hayer-Hartl, M., Converging concepts of protein folding in vitro and in vivo. Nat. Struct. Mol. Biol. 2009, 16, 574-581.

[23] Upadhyay, A. K., Murmu, A., Singh, A., Panda, A. K., Kinetics of inclusion body formation and its correlation with the characteristics of protein aggregates in Escherichia coli. PLoS One 2012, 7, e33951.

[24] Hart, R. A., Rinas, U., Bailey, J. E., Protein composition of Vitreoscilla hemoglobin inclusion bodies produced in Escherichia coli. J. Biol. Chem. 1990, 265, 12728-12733.

[25] Basu, A., Li, X., Leong, S. S. J., Refolding of proteins from inclusion bodies: rational design and recipes. Appl. Micobiol. Biotech. 2011, 92, 241.

[26] Burgess, R. R., Refolding solubilized inclusion body proteins. Methods Enzymol. 2009, 463, 259-282.

[27] Freydell, E. J., van der Wielen, L. A. M., Eppink, M. H. M., Ottens, M., Techno-economic evaluation of an inclusion body solubilization and recombinant protein refolding process. Biotechnol. Progr. 2011, 27, 1315-1328.

[28] Maxwell, K. L., Bona, D., Liu, C., Arrowsmith, C. H. et al., Refolding out of guanidine hydrochloride is an effective approach for highthroughput structural studies of small proteins. Protein Sci. 2003, 12, 2073-2080. 
[29] Mahmoodi, M., Ghodsi, M., Moghadam, M., Sankian, M., Pulsed Dilution Method for the recovery of aggregated mouse TNF- $\alpha$. Rep. Biochem. Mol. Biol. 2017, 5, 103-107.

[30] Tsumoto, K., Ejima, D., Kumagai, I., Arakawa, T., Practical considerations in refolding proteins from inclusion bodies. Protein Expression Purif. 2003, 28, 1-8.

[31] St. John, R. J., Carpenter, J. F., Randolph, T. W., High pressure fosters protein refolding from aggregates at high concentrations. Proc. Natl. Acad. Sci. U.S.A. 1999, 96, 13029-13033.

[32] Seefeldt, M. B., Ouyang, J., Froland, W. A., Carpenter, J. F. et al., High-pressure refolding of bikunin: Efficacy and thermodynamics. Protein Sci. 2004, 13, 2639-2650.

[33] Lazaridis, T., Lee, I., Karplus, M., Dynamics and unfolding pathways of a hyperthermophilic and a mesophilic rubredoxin. Protein Sci. 1997, 6, 2589-2605.

[34] Gueguen, Y., Voorhorst, W. G., van der Oost, J., de Vos, W. M., Molecular and biochemical characterization of an endo-beta-1,3glucanase of the hyperthermophilic archaeon Pyrococcus furiosus. J. Biol. Chem. 1997, 272, 31258-31264.

[35] Kaper, T., Verhees, C. H., Lebbink, J. H., van Lieshout, J. F. et al., Characterization of beta-glycosylhydrolases from Pyrococcus furiosus. Methods Enzymol. 2001, 330, 329-346.

[36] Ippel, J. H., Koutsopoulos, S., Nabuurs, S. M., van Berkel, W. J. H. et al., NMR characterization of a 264-residue hyperthermostable endo-beta1,3-glucanase. Biochem. Biophys. Res. Commun. 2010, 391, 370-375.

[37] Ilari, A., Fiorillo, A., Angelaccio, S., Florio, R. et al., Crystal structure of a family 16 endoglucanase from the hyperthermophile Pyrococcus furiosus--structural basis of substrate recognition. FEBS J. 2009, 276 , 1048-1058.

[38] Chiaraluce, R., van der Oost, J., Lebbink, J. H. G., Kaper, T. et al., Persistence of tertiary structure in 7.9 M guanidinium chloride: The case of endo-beta-1,3-glucanase from Pyrococcus furiosus. Biochemistry 2002, 41, 14624-14632.

[39] Laemmli, U. K., Cleavage of structural proteins during the assembly of the head of bacteriophage T4. Nature 1970, 227, 680-685.
[40] Provencher, S. W., Contin - a general-purpose constrained regularization program for inverting noisy linear algebraic and integralequations. Comput. Phys. Commun. 1982, 27, 229-242.

[41] Lyman Davidson, D., Laboratory experiments in biological chemistry. J. Chem. Educ. 1944, 21, 570.

[42] Koutsopoulos, S., Tjeerdsma, A. M., Lieshout, J. F., van der Oost, J. et al., In situ structure and activity studies of an enzyme adsorbed on spectroscopically undetectable particles. Biomacromolecules 2005, 6, 1176-1184.

[43] Greenfield, N., Fasman, G. D., Computed circular dichroism spectra for the evaluation of protein conformation. Biochemistry 1969, 8, 4108-4116.

[44] Lee, Y., Zhou, T., Tartaglia, G. G., Vendruscolo, M. et al., Translationally optimal codons associate with aggregation-prone sites in proteins. Proteomics 2010, 10, 4163-4171.

[45] Koutsopoulos, S., van der Oost, J., Norde, W., Conformational studies of a hyperthermostable enzyme. FEBS J. 2005, 272, 5484-5496.

[46] Chiaraluce, R., Florio, R., Angelaccio, S., Gianese, G. et al., Tertiary structure in $7.9 \mathrm{M}$ guanidinium chloride-the role of Glu53 and Asp287 in Pyrococcus furiosus endo-beta-1,3-glucanase. FEBS J. 2007, 274, 6167-6179.

[47] Peng, S., Chu, Z., Lu, J., Li, D. et al., Co-expression of chaperones from $P$. furiosus enhanced the soluble expression of the recombinant hyperthermophilic $\alpha$-amylase in $E$. coli. Cell Stress Chaperones 2016, 21, 477-484.

[48] Bemporad, F., Chiti, F., "Native-like aggregation" of the acylphosphatase from Sulfolobus solfataricus and its biological implications. FEBS Lett. 2009, 583, 2630-2638

[49] Mason, P. E., Neilson, G. W., Dempsey, C. E., Barnes, A. C. et al., The hydration structure of guanidinium and thiocyanate ions: implications for protein stability in aqueous solution. Proc. Natl. Acad. Sci. U.S.A. 2003, 100, 4557-4561. 


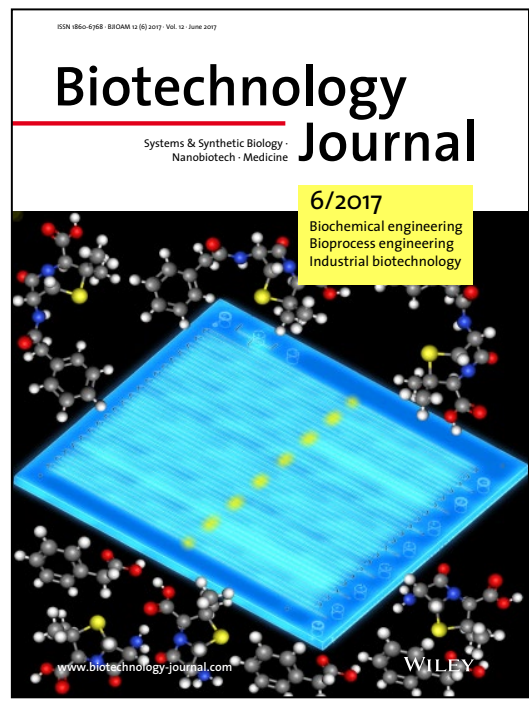

Cover illustration

Schematic representation of a microfluidic side-entry reactor with reactants of a penicillin $\mathrm{G}$ acylase reaction and $\mathrm{pH}$ sensors integrated along the reaction channel. The $\mathrm{pH}$ sensors enabled real-time monitoring of the reaction progress in a microfluidic reactor. Alkaline buffers added to the reactor's side-entries balanced the $\mathrm{pH}$ and increased product yield, thereby highlighting the feasibility of $\mathrm{pH}$ control. The cover is prepared by Pia Gruber, Marco P.C. Marques, Philipp Sulzer, Roland Wohlgemuth, Torsten Mayr, Frank Baganz and Nicolas Szita authors of the article "Real-time $\mathrm{pH}$ monitoring of industrially relevant enzymatic reactions in a microfluidic side-entry reactor ( $\mu S E R)$ shows potential for pH control" (https://doi.org/10.1002/biot.201600475).

Biotechnology Journal - list of articles published in the June 2017 issue.

Mini-Review

Compartmentalized metabolic engineering for biochemical and biofuel production

Herbert M. Huttanus and Xueyang Feng

https://doi.org/10.1002/biot.201700052

Research Article

Continuous desalting of refolded protein solution improves capturing in ion exchange chromatography: A seamless process Nicole Walch and Alois Jungbauer

https://doi.org/10.1002/biot.201700082

Research Article

Real-time pH monitoring of industrially relevant enzymatic reactions in a microfluidic side-entry reactor ( $\mu$ SER) shows potential for $\mathrm{pH}$ control

Pia Gruber, Marco P.C. Marques, Philipp Sulzer, Roland

Wohlgemuth, Torsten Mayr, Frank Baganz and Nicolas Szita

https://doi.org/10.1002/biot.201600475

Research Article

High throughput inclusion body sizing:

Nano particle tracking analysis

Wieland N. Reichelt, Andreas Kaineder, Markus Brillmann, Lukas Neutsch, Alexander Taschauer, Hans Lohninger and Christoph Herwig

https://doi.org/10.1002/biot.201600471

Research Article

Experimental validation of in silico estimated biomass yields of Pseudomonas putida KT2440

Sarah B. Hintermayer and Dirk Weuster-Botz

https://doi.org/10.1002/biot.201600720
Research Article

A fine-tuned composition of protein nanofibrils yields an upgraded functionality of displayed antibody binding domains Benjamin Schmuck, Mats Sandgren and Torleif Härd

https://doi.org/10.1002/biot.201600672

Reasearch Article

Biocatalytic virus capsid as nanovehicle for enzymatic activation of Tamoxifen in tumor cells

Alejandro Tapia-Moreno, Karla Juarez-Moreno,

Oscar Gonzalez-Davis, Ruben D. Cadena-Nava and

Rafael Vazquez-Duhalt

https://doi.org/10.1002/biot.201600706

Research Article

A cleavable self-assembling tag strategy for preparing proteins and peptides with an authentic N-terminus

Qing Zhao, Bihong Zhou, Xianxing Gao, Lei Xing, Xu Wang and Zhanglin Lin

https://doi.org/10.1002/biot.201600656

Research Article

Chaotropic heat treatment resolves native-like aggregation of a heterologously produced hyperthermostable laminarinase Adrie H. Westphal, Astrid A. Geerke-Volmer,

Carlo P. M. van Mierlo and Willem J. H. van Berkel

https://doi.org/10.1002/biot.201700007

Biotech Method

A single-step FACS sorting strategy in conjunction with fluorescent vital dye imaging efficiently assures clonality of biopharmaceutical production cell lines Jürgen Fieder, Patrick Schulz, Ingo Gorr, Harald Bradl and Till Wenger

https://doi.org/10.1002/biot.201700002 